\title{
Characterization of a mouse model of plague after aerosolization of Yersinia pestis CO92
}

\author{
Stacy L. Agar, ${ }^{1}$ Jian Sha, ${ }^{1}$ Sheri M. Foltz, ${ }^{1}$ Tatiana E. Erova, ${ }^{1}$ \\ Kristin G. Walberg, ${ }^{1}$ Todd E. Parham, ${ }^{1}$ Wallace B. Baze, ${ }^{3}$ Giovanni Suarez, ${ }^{1}$ \\ Johnny W. Peterson ${ }^{1,2}$ and Ashok K. Chopra ${ }^{1,2}$ \\ ${ }^{1}$ Departments of Microbiology and Immunology, University of Texas Medical Branch, Galveston, \\ TX 77555, USA \\ ${ }^{2}$ Center for Biodefense and Emerging Infections and Sealy Center for Vaccine Development, \\ University of Texas Medical Branch, Galveston, TX 77555, USA \\ ${ }^{3}$ University of Texas M. D. Anderson Cancer Center, Bastrop, TX 78602, USA
}

Correspondence

Ashok K. Chopra

achopra@utmb.edu

Received 4 February 2008

Revised 5 March 2008

Accepted 26 March 2008

\begin{abstract}
Yersinia pestis is a Gram-negative bacterium, and the causative agent of bubonic plague and pneumonic plague. Because of its potential use as a biological warfare weapon, the plague bacterium has been placed on the list of category A select agents. The dynamics of pneumonic infection following aerosolization of the highly virulent $Y$. pestis CO92 strain have been poorly studied; therefore, the purpose of this study was to determine the LD $_{50}$ dose, bacterial dissemination, cytokine/chemokine production and tissue damage in Swiss-Webster mice over a $72 \mathrm{~h}$ course of infection. We exposed mice in a whole-body Madison chamber to various doses of $Y$. pestis CO92 aerosolized by a Collison nebulizer, and determined that the $\mathrm{LD}_{50}$ presented dose (Dp) of the bacterium in the lungs was $2.1 \times 10^{3}$ c.f.u. In a subsequent study, we infected mice at a $\mathrm{Dp}$ of $1.3 \times 10^{4}$ c.f.u., and harvested organs and blood at $1,24,48$ and 72 h postinfection. Histopathological examination, in addition to measurement of bacterial dissemination and cytokine/chemokine analysis, indicated progressive tissue injury, and an increased number of animals succumbing to infection over the course of the experiment. Using these data, we were able to characterize the mouse plague model following aerosolization of $Y$. pestis CO92.
\end{abstract}

\section{INTRODUCTION}

Yersinia pestis is a current health threat in many parts of the world, and a potential bioweapon (Krishna \& Chitkara, 2003). The majority of cases of human plague are of the bubonic form, and occur naturally following the bite of an infected flea (Perry \& Fetherston, 1997). In these cases, disease progression is gradual, and can be ameliorated by antibiotic treatment. Infection can also be of the pneumonic or septicaemic form, both of which have high mortality rates, especially if the antibiotic treatment is delayed (Gradon, 2002). Humans with primary pneumonic plague initially experience a febrile illness with headaches and chills, and a rapid progression to fulminant pneumonia, resulting in death within $72 \mathrm{~h}$ post-infection (p.i.) (Inglesby et al., 2000; Perry \& Fetherston, 1997; Riedel, 2005).

Abbreviations: $\mathrm{C}_{n e b}$, bacterial concentration after nebulization; Dp, bacterial dose presented; G-CSF, granulocyte colony-stimulating factor; GM-CSF, granulocyte macrophage colony-stimulating factor; IFN, interferon; IL, interleukin; KC, human equivalent of IL-8; MCP, macrophage chemoattractant protein; MIP, macrophage inflammatory protein; p.i., post-infection; TNF, tumour necrosis factor.
Although outbreaks of pneumonic plague are rare, cases were reported in Manchuria in the early 20th century, and later in Madagascar (Inglesby et al., 2000). Y. pestis, a category A select agent, is easily cultivated, and causes rapid damage in humans when introduced via the aerosolized route (Inglesby et al., 2000). Furthermore, intentional release of the bacteria would most likely occur by this route (Inglesby et al., 2000). In fact, Y. pestis was used as a biological weapon against China during World War II, and it has been a focus of subsequent bioweapon development programmes in the USA and the former Soviet Union (Inglesby et al., 2000).

Some information regarding pneumonic disease presentation in mice, and the response of the host to infection following intranasal administration of the bacterium, has been reported (Bubeck et al., 2007; Lathem et al., 2005, 2007; Sha et al., 2008). Intranasal entry facilitates channelling of the bacteria into the bloodstream, bypassing the lymphatics, resulting in a rapid dissemination of bacteria to the other organs of the body. Additionally, a biphasic response (an anti-inflammatory phase followed by a proinflammatory phase) has been noted after intranasal 
administration of $Y$. pestis $\mathrm{CO} 92$ to mice, and this was indicative of a delay in the response of the host to infection (Lathem et al., 2005). Although difficult to test, as strains of $Y$. pestis that are negative for type III secretion system do not establish serious infections in vivo, it is presumed that the early anti-inflammatory response $(24-36 \mathrm{~h} \mathrm{p.i.)}$ is induced by the type III secretion system and its associated effectors, while the later proinflammatory response (36$72 \mathrm{~h}$ p.i.) results from from the production of various cytokines and chemokines [e.g. interleukin (IL)-6, macrophage chemoattractant protein (MCP)-1, etc.]. In our most recent study, we observed a time-associated progression of plague bacterial dissemination ranging between 72 and $96 \mathrm{~h}$ following an intranasal inoculation of mice, as well as rises in cytokine and chemokine levels, and an increase in the severity of tissue injury (Sha et al., 2008). At a $5 \mathrm{LD}_{50}$ dose of $Y$. pestis CO92, the majority of the mice succumbed to infection and died when infected by the intranasal route (Sha et al., 2008). Smith et al. reported the development of pneumonic plague in mice via the aerosolization of $Y$. pestis (Smith et al., 1957), and, since then, several studies have utilized an aerosol model to test the efficacies of plague vaccine combinations (Anderson et al., 1996; Andrews et al., 1996; Glynn et al., 2005; Heath et al., 1998; Hill et al., 2006; Jones et al., 2006; Williamson et al., 2007). However, currently there are no reports detailing the kinetics of pneumonic plague development and host immune response by aerosolization of virulent $Y$. pestis CO92 in mice. Therefore, the present study was designed to examine the disease progression, cytokine release and tissue injury that resulted from the aerosolization of virulent $Y$. pestis CO92 in a mouse model.

\section{METHODS}

Bacterial growth conditions. Virulent $Y$. pestis strain CO92 (Doll et al., 1994), which is naturally resistant to polymyxin B (Cathelyn et al., 2006), was obtained from the Centers for Disease Control and Prevention (CDC), Atlanta, GA, USA. To prepare Y. pestis CO92 for aerosolization, we followed the protocol published by Anderson et al. (1996), with some modifications. Briefly, $10 \mu \mathrm{l}$ bacterial glycerol stock was streaked onto sheep blood agar (SBA; Teknova), and incubated at $28{ }^{\circ} \mathrm{C}$ for $48 \mathrm{~h}$. Colonies were removed from the plate using a sterile loop, and a suspension was made using heart infusion broth (HIB; Difco). The optical density of the bacterial suspension at $620 \mathrm{~nm}$ was adjusted to 1.0 ( $1: 7$ dilution, yielding approximately $10^{9}$ c.f.u. $\mathrm{ml}^{-1}$ ). Finally, $2 \mathrm{ml}$ of the diluted suspension was used to inoculate $100 \mathrm{ml}$ HIB enriched with $0.2 \%$ xylose (DL-xylose; Sigma-Aldrich), and the broth was incubated for $24 \mathrm{~h}$ at $30{ }^{\circ} \mathrm{C}$, with shaking at 100 r.p.m. We preferred to grow bacteria at $30{ }^{\circ} \mathrm{C}$ rather than $37{ }^{\circ} \mathrm{C}$ to avoid possible complications of aerosolizing $Y$. pestis with capsule, as the latter is optimally synthesized at $37{ }^{\circ} \mathrm{C}$. Further, since $30{ }^{\circ} \mathrm{C}$ is closer to the optimal growth temperature of yersiniae, we were able to achieve the higher bacterial concentrations needed for aerosolization. Following incubation, the suspension was centrifuged at 5000 r.p.m. for $10 \mathrm{~min}$ in an Avanti J-20 refrigerated centrifuge fitted with HEPA filters (Beckman-Coulter), and the pellet was washed twice in HIB before it was resuspended in $10 \mathrm{ml}$ HIB (yielding approx. $10^{10}$ c.f.u. $\mathrm{ml}^{-1}$ ). Prior to aerosolization, the bacterial pellet was washed in water, and additional dilutions were made in water to obtain different cell densities used to precisely calculate the $\mathrm{LD}_{50}$ dose.
Antifoam A emulsion 240 (30 $\mu$ l; Sigma-Aldrich) was added to each bacterial suspension prior to the aerosolization procedure. The bacterial cultivation was conducted in our restricted entry Biosafety Level-2 laboratory approved by the CDC.

Aerosol challenge of mice. Our study was conducted under an animal protocol approved by the University of Texas Medical Branch Institutional Animal Care and Use Committee. Mice were exposed to $Y$. pestis CO92 aerosols in a whole-body Madison chamber (Madison), which was attached in tandem to a class III biological glove cabinet (Baker Company IsoGARD 14), and then to a class II biological safety cabinet, as previously described (Peterson et al., 2007). Aerosolization of the pathogen was conducted in the aerobiology suite within the restricted access Animal Biosafety Level 3 laboratory. Female 5- to 6-week-old Swiss-Webster mice were purchased from Charles River Laboratories. Various concentrations of $Y$. pestis $\mathrm{CO} 92$ were aerosolized using a three-jet Collison nebulizer, and mice were exposed to the pathogen for $15 \mathrm{~min}$ while the aerosol chamber was flushed with air at a flow rate of $501 \mathrm{~min}^{-1}$, as described recently for Bacillus anthracis spores (Peterson et al., 2007).

Histopathology. At 1, 24, 48 and 72 h p.i., lung, liver, spleen and heart tissues from $Y$. pestis-infected mice (five mice per time point) were collected in screw-cap containers at necropsy, and immersionfixed in $10 \%$ neutral, buffered formalin. The tissues remained in this solution for 3 days, after which they were placed in new vials with fresh formalin, examined for sterility, routinely processed, sectioned at $5 \mu \mathrm{m}$, mounted on glass slides, and stained with haematoxylin and eosin. Bacteria were easily seen in infected tissues using this stain, but we also used Giemsa stain to visualize bacteria in tissues when needed (Sha et al., 2008). Light microscopic evaluation of the tissues was then performed. The lesions resulting from $Y$. pestis infection have been previously described (Sha et al., 2008), and they were graded based on a severity scale correlating with estimates of lesion distribution and type, ranging from minimal to severe (minimal, 2-10\%; mild, 10 $20 \%$; moderate, $20-50 \%$; severe, $>50 \%$ ). Briefly, acute inflammation indicated the presence of neutrophils, while subacute inflammation suggested a mixture of neutrophils and mononuclear cells. Oedema and necrosis were observed in tissues having both acute and subacute inflammation accompanied by either moderate or severe lesions. We analysed tissues from five animals per group, and presented the data from representative tissues.

Bacterial dissemination. Mice were exposed to a $6 \mathrm{LD}_{50}$ dose of aerosolized $Y$. pestis CO92. Beginning at $1 \mathrm{~h}$ p.i., and continuing at 24, 48 and $72 \mathrm{~h}$ p.i., groups of five mice were killed using a mixture of ketamine $\left(90 \mathrm{mg} \mathrm{kg}^{-1}\right)$ and xylazine $\left(10 \mathrm{mg} \mathrm{kg}^{-1}\right)$, and the lungs, liver, spleen and heart were removed immediately after death had been ensured by cervical dislocation. We drew blood from the heart before cervical dislocation of the animals. The organs were weighed, and homogenized in $1 \mathrm{ml}$ sterile water containing $25 \mu \mathrm{g} \mathrm{ml}$ polymyxin B (to facilitate specific growth of $Y$. pestis CO92) using tissue grinders (Kendall). The blood and tissue homogenates were serially diluted in sterile water with polymyxin B, and cultured on SBA. Plates were incubated at $28{ }^{\circ} \mathrm{C}$ for $48 \mathrm{~h}$, after which bacterial colonies were counted, and c.f.u. per gram of tissue or per millilitre of blood was calculated.

In vivo cytokine analysis. Mice were exposed to a $6 \mathrm{LD}_{50}$ dose of aerosolized $Y$. pestis CO92. Beginning at $1 \mathrm{~h}$ p.i., and continuing at 24, 48 and $72 \mathrm{~h}$ p.i., groups of five mice were killed; organs were harvested at every time point, and blood was collected via cardiac puncture from the 1 and $72 \mathrm{~h}$ p.i. groups for cytokine analysis. Sera were filtered once through a $0.45 \mu \mathrm{m}$ syringe filter, and then once through a $0.22 \mu \mathrm{m}$ syringe filter, before they were cultured on SBA to confirm that bacteria had been successfully removed from the samples prior to analysis. The levels of 23 different cytokines and chemokines 
were measured using the multiplex assay with Bio-Plex (Bio-Rad), as previously described (Sha et al., 2008).

Statistical analyses. Kaplan-Meier survival estimates of 10 mice per group were used for comparison of the $\mathrm{LD}_{50}$ survival curves. Whenever appropriate, Student's $t$-test, or ANOVA with Bonferroni post-test, was utilized for statistical analysis between groups. The $\mathrm{LD}_{50}$ determination experiments were repeated twice with 10 mice per dose of the bacteria. For studies on bacterial dissemination and cytokine profiling, we used 15 mice: five were used for collection of tissues and blood, while 10 were observed for mortality. The latter experiment was repeated twice.

\section{RESULTS AND DISCUSSION}

\section{Murine model for developing pneumonic plague by aerosolization of $Y$. pestis $\mathrm{CO} 2$}

There have been a limited number of studies performed on aerosolized $Y$. pestis in the murine model, therefore our first goal was to calculate the precise $\mathrm{LD}_{50}$ dose of $Y$. pestis using a whole-body aerosol chamber. Four groups of 10 mice each were exposed to $Y$. pestis $\mathrm{CO} 92$, which was prepared as described in Methods, and diluted so that the nebulizer concentrations of bacteria prior to aerosolization were $1.0 \times 10^{7}, \quad 1.0 \times 10^{8}, \quad 1.0 \times 10^{9}$ and $1.0 \times 10^{10}$ c.f.u. $\mathrm{ml}^{-1}$. Nebulization consistently resulted in a decrease of approximately $1 \log$ in the number of bacteria introduced into the aerosolization chamber. Therefore, the resulting bacterial suspension concentrations $\left(\mathrm{C}_{\text {neb }}\right)$, after nebulization, were $4.0 \times 10^{6}, \quad 3.7 \times 10^{7}, \quad 4.5 \times 10^{8}$ and $2.0 \times 10^{9}$ c.f.u. $\mathrm{ml}^{-1}$, respectively (Fig. 1).

The bacterial dose presented $(\mathrm{Dp})$ to the lungs of each animal inside the Madison chamber was based on Guyton's

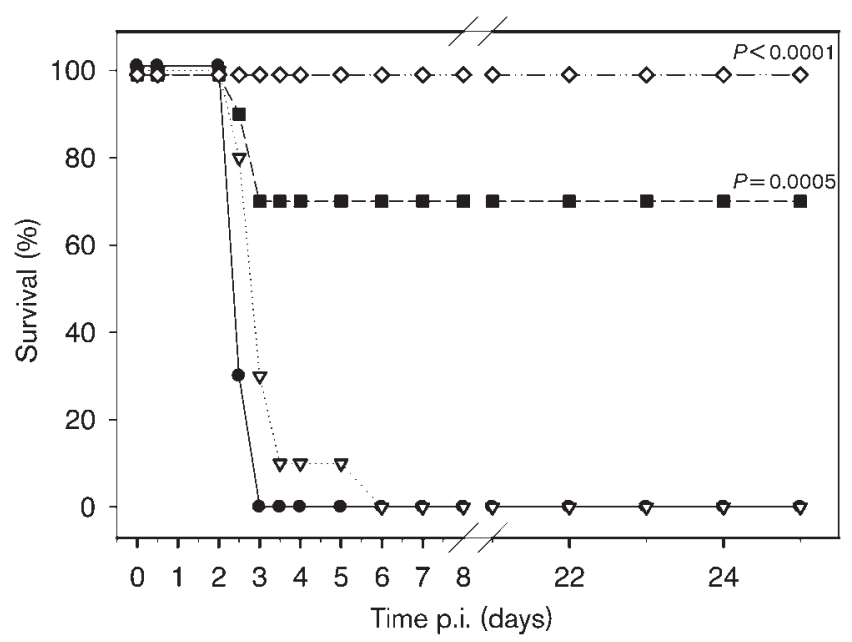

Fig. 1. Calculation of the $\mathrm{LD}_{50}$ for aerosolized $Y$. pestis CO92. Groups of 10 female Swiss-Webster mice each were aerosolized with four doses $\left(\mathrm{C}_{n e b}\right)$ of $Y$. pestis: $4.0 \times 10^{6}(\diamond), 3.5 \times 10^{7}(\boldsymbol{\square})$, $4.5 \times 10^{8}(\nabla)$ and $2.0 \times 10^{9}(-)$ c.f.u. $\mathrm{ml}^{-1}$. The $\mathrm{LD}_{50}$, based on the $\mathrm{Dp}$, was calculated to be $2.1 \times 10^{3}$ c.f.u. The $P$ values, as compared with the highest challenge dose, are shown. formula for the measurement of respiratory volumes (Guyton, 1947), the algorithms for which have been described (Roy \& Pitt, 2005). At the highest $\mathrm{C}_{\text {neb }}$, the Dp was calculated to be $1.3 \times 10^{4}$ c.f.u. $\mathrm{ml}^{-1}$, while the lowest $\mathrm{C}_{\text {neb }}\left(4.0 \times 10^{6}\right.$ c.f.u. $\left.\mathrm{ml}^{-1}\right)$ resulted in a $\mathrm{Dp}$ of 16 c.f.u. $\mathrm{ml}^{-1}$. The mice in this study began to die at $60 \mathrm{~h}$ p.i., and the majority died between 72 and 96 h p.i.; this time frame is similar to that of our previous study using intranasal challenge (Sha et al., 2008). The Dp $\mathrm{LD}_{50}$ for Y. pestis CO92 in Swiss-Webster mice was calculated to be $2.1 \times 10^{3}$ c.f.u. in the whole-body chamber, and this was $1 \log$ less than that reported $\left(2.0 \times 10^{4}\right.$ c.f.u. $)$ using either the nose-only exposure system (Anderson et al., 1996) or the whole-body chamber (Glynn et al., 2005) and the same mouse strain. These differences might be explained by variations in the aerosolization procedures, or whether the number of bacteria in the nebulizer was calculated before or after aerosolization.

Interestingly, the $\mathrm{LD}_{50}$ dose we previously calculated for intranasal administration of $Y$. pestis to the same species of mice was 340 c.f.u. (Sha et al., 2008). These differences in the calculated $\mathrm{LD}_{50}$ doses between two pneumonic models (intranasal versus aerosol) might be due to the mode and efficiency of bacterial entry into the lungs. Alternatively, the lower $\mathrm{LD}_{50}$ dose of $Y$. pestis $\mathrm{CO} 92$ via the intranasal versus the aerosol route might be due to nebulization during aerosolization, as this could affect virulence determinant(s) (e.g. pili, toxins, etc.) present on the bacterial surface; this would thereby increase the number of bacteria necessary to cause infection via the aerosolized route.

\section{Histopathology following aerosolization}

To assess tissue injury occurring following aerosoladministered $Y$. pestis (Dp $1.3 \times 10^{4}$ c.f.u. $\mathrm{ml}^{-1}$ ) in mice, we killed five animals at 1, 24, 48 and $72 \mathrm{~h}$ p.i., and harvested and formalin-fixed the lungs, liver, spleen and heart. For brevity, histopathology is shown for control animals $(1 \mathrm{~h}$ p.i.) and animals at $72 \mathrm{~h}$ p.i. in Fig. 2. The animal tissues harvested $1 \mathrm{~h}$ p.i. served as appropriate negative controls, as we noted in our previous aerosol studies (data not shown) that animals $1 \mathrm{~h}$ post-diluent (no bacteria) exposure showed neither pathology nor alterations in cytokine and chemokine levels compared with uninfected mice that had not been subjected to aerosolization of the diluent.

Animals infected and examined at $1 \mathrm{~h}$ p.i. had no lesions in the lung, liver, spleen or heart, and served as controls (Fig. $2 \mathrm{~A}-\mathrm{D})$. At $24 \mathrm{~h}$ p.i., three of the mice had acute inflammation in the lungs, usually in association with blood vessels. Two of the five mice had small areas of minimal acute inflammation and necrosis in the liver. One of these mice had a mild inflammatory cell (neutrophilic) infiltrate in the red pulp of the spleen (data not shown). There were no significant lesions present in the hearts of any of the five mice. 

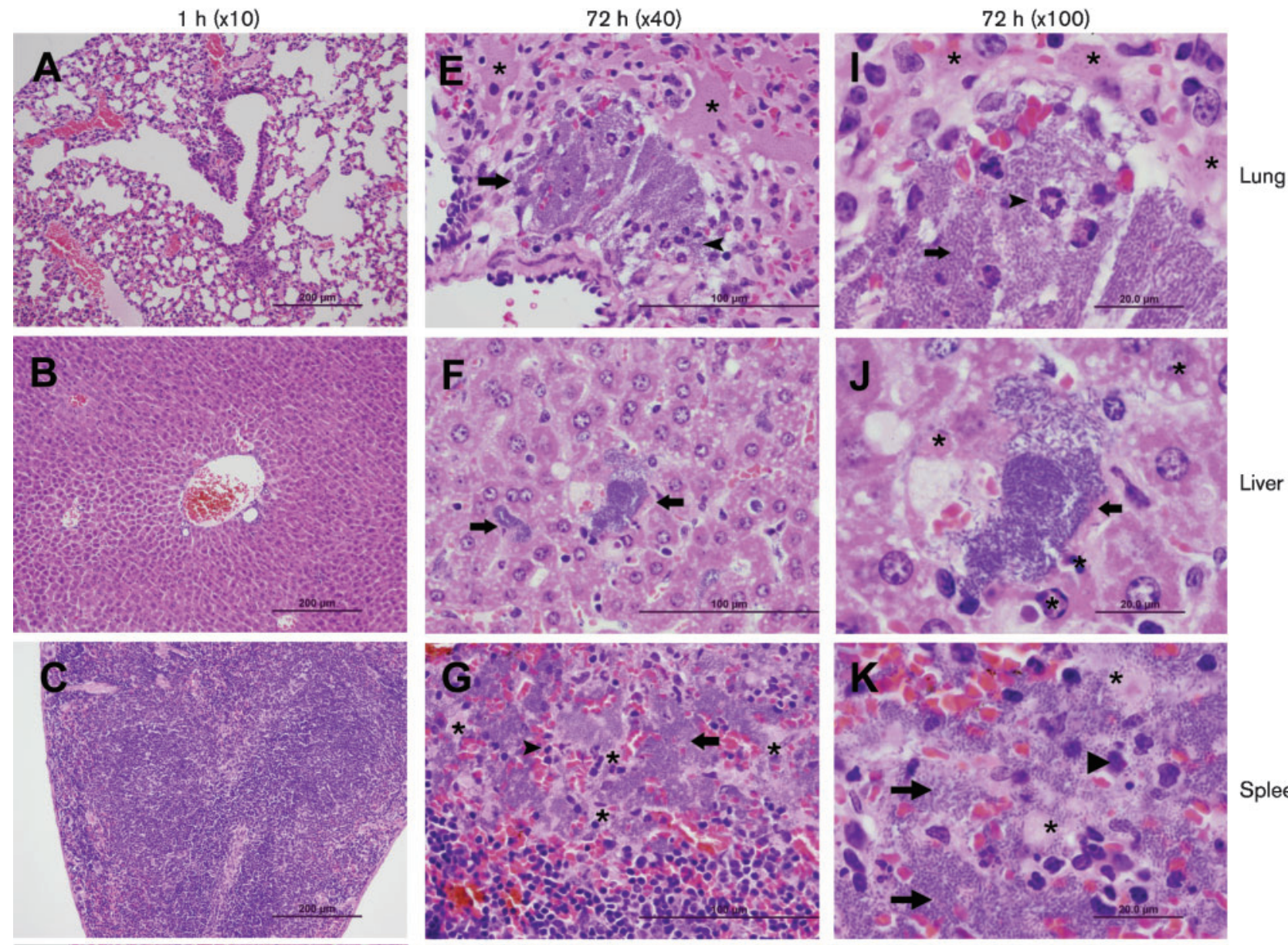

Spleen
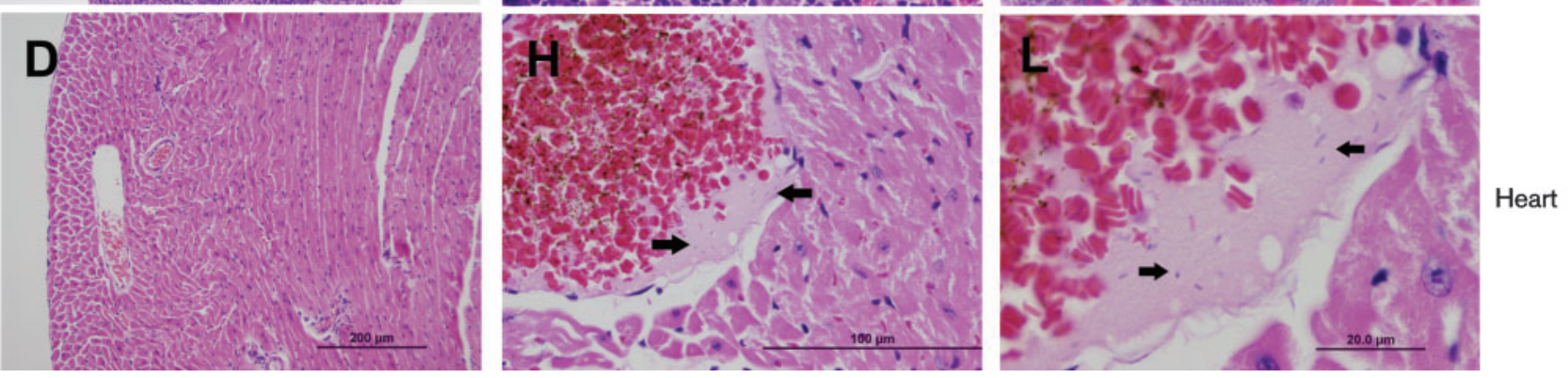

Fig. 2. Histopathology of mouse tissue $72 \mathrm{~h}$ after exposure to aerosolized $Y$. pestis. (A-D) Tissue samples (lungs, liver, spleen and heart, respectively) at $1 \mathrm{~h}$ following exposure represent negative controls. At $72 \mathrm{~h}$ p.i., the mouse lungs showed large clumps of bacteria ( $E$ and I, arrows), with oedema (asterisks) and smaller groups of bacteria. Acute inflammatory cells (arrowhead) were present within the larger bacterial clump. The livers contained several large clumps of bacteria (F and J, arrows) in the parenchyma, and some hepatocytes near the bacteria were necrotic (asterisks). The spleens contained large clumps of bacteria ( $\mathrm{G}$ and $\mathrm{K}$, arrows), with oedema (asterisks) and necrotic and acute inflammatory cells (arrowheads). The hearts contained intravascular bacteria ( $H$ and L, arrows) within a blood vessel. Bars: (A-D), $200 \mu \mathrm{m} ;(E-H), 100 \mu \mathrm{m} ;(I-L)$, $20 \mu \mathrm{m}$. All sections were stained with haematoxylin and eosin. Lower magnification data are shown for the control tissues ( $1 \mathrm{~h}$ p.i.) to cover larger areas of the tissues to provide convincing evidence that there was no pathology seen in these tissues.

At $48 \mathrm{~h}$ p.i., four of the five mice had lung inflammation associated with blood vessels, as observed in the $24 \mathrm{~h}$ p.i. mice. Four of the mice had mild acute inflammation and liver necrosis, with occasional bacteria observed in one of the animals. The spleens of three of the mice exhibited neutrophilic infiltrates and some necrotic cells in the red pulp (data not shown). There were no significant lesions present in the hearts of any mice at $48 \mathrm{~h}$ p.i. 
At $72 \mathrm{~h}$ p.i., the mice infected with the highest presented dose of bacteria $\left(1.3 \times 10^{4}\right.$ c.f.u. $\left.\mathrm{ml}^{-1}\right)$ began to die, and this was reflected in the histopathology of their tissues. The lungs of all mice were inflamed (Fig. 2E, I, inflammatory cells indicated by arrowheads) as in the 24 and $48 \mathrm{~h}$ p.i. groups, but the reaction was more prominent with oedema (asterisks), and the presence of small-to-large groups of bacteria (arrows); these characteristics are common in pneumonic plague infections (Inglesby et al., 2000). All mice had acute inflammatory changes in the liver, with necrosis (Fig. 2F, J,
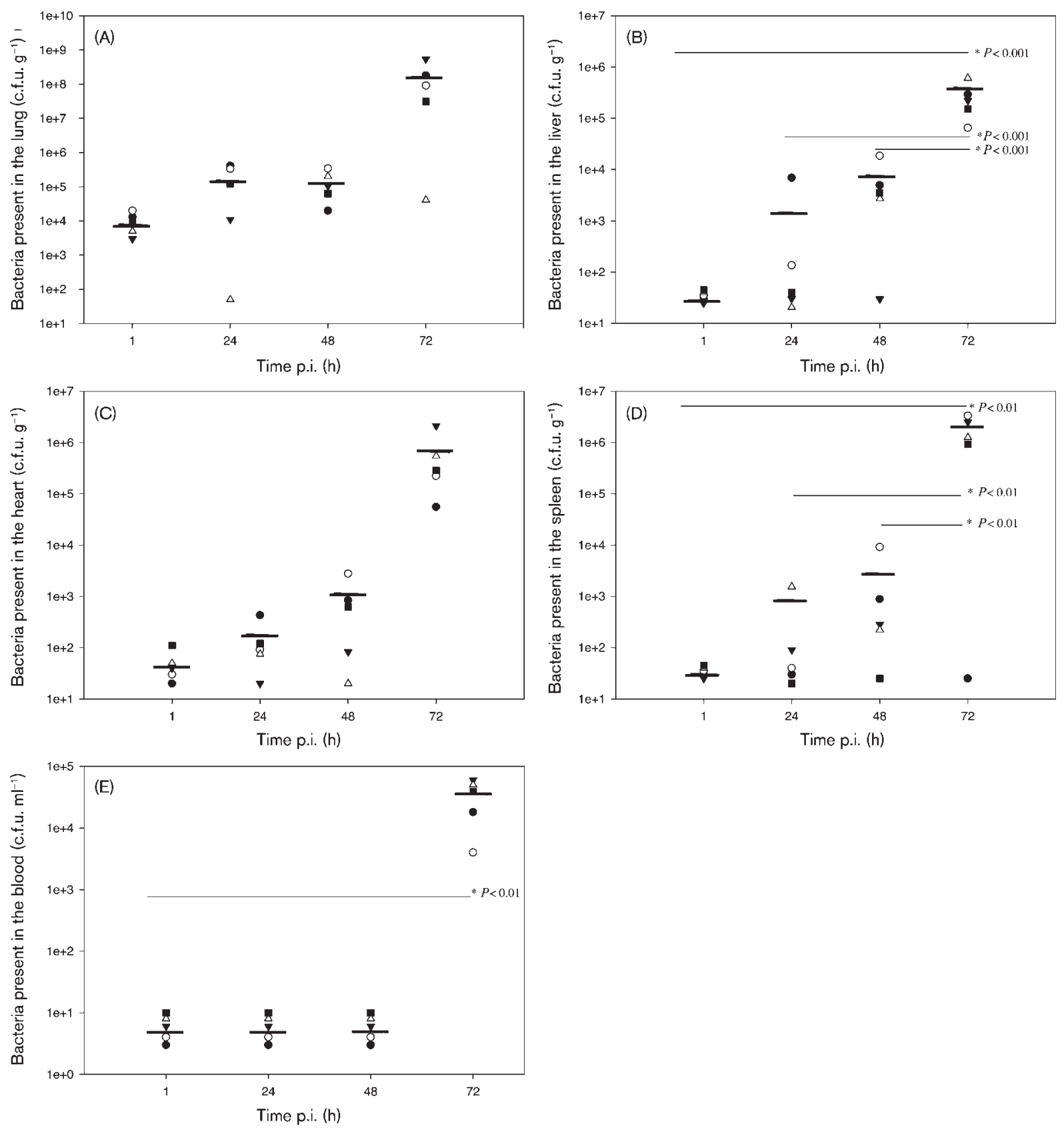

Fig. 3. Dissemination of $Y$. pestis CO92 through the organs of mice from $1 \mathrm{~h}$ to $72 \mathrm{~h}$ p.i. Following aerosolization, five mice per group were killed at 1, 24, 48 and 72 h p.i. (20 mice in total). The lungs (A), liver (B), heart (C) and spleen (D) of each animal were homogenized, and the blood (E) was collected. All tissues were cultured on SBA to assess the kinetics of $Y$. pestis dissemination. Data were plotted on a log scale to allow visualization of all of the data points; however, overlapping at various time points did occur. The detectable limit of bacteria was approximately 80 c.f.u. (g tissue $)^{-1}$. The horizontal bars represent the mean number of bacteria present at each time point. The five symbols represent five different mice at each time point. *Significant increases in the number of bacteria over time; $P$ values (ANOVA) are indicated. 
asterisks), the presence of fibrin, and a variable number of rod-shaped bacteria (arrows). All five mice had moderate lymphoid depletion in the white pulp of the spleen, and variable numbers of bacteria (Fig. 2G, K, arrows), with congestion, oedema (at asterisks), and fibrin and cellular loss in the red pulp. The spleen was also infiltrated with inflammatory cells (arrowheads). The heart showed occasional intravascular bacteria (Fig. 2H, L, arrows). Using Giemsa staining, we also noted the presence of $Y$. pestis (based on size and morphology) in different organs of infected mice.

We noticed a relatively rapid onset of infection, resulting in the death of the animals within 72-96 h p.i. after exposure to aerosolized $Y$. pestis CO92. This is in agreement with
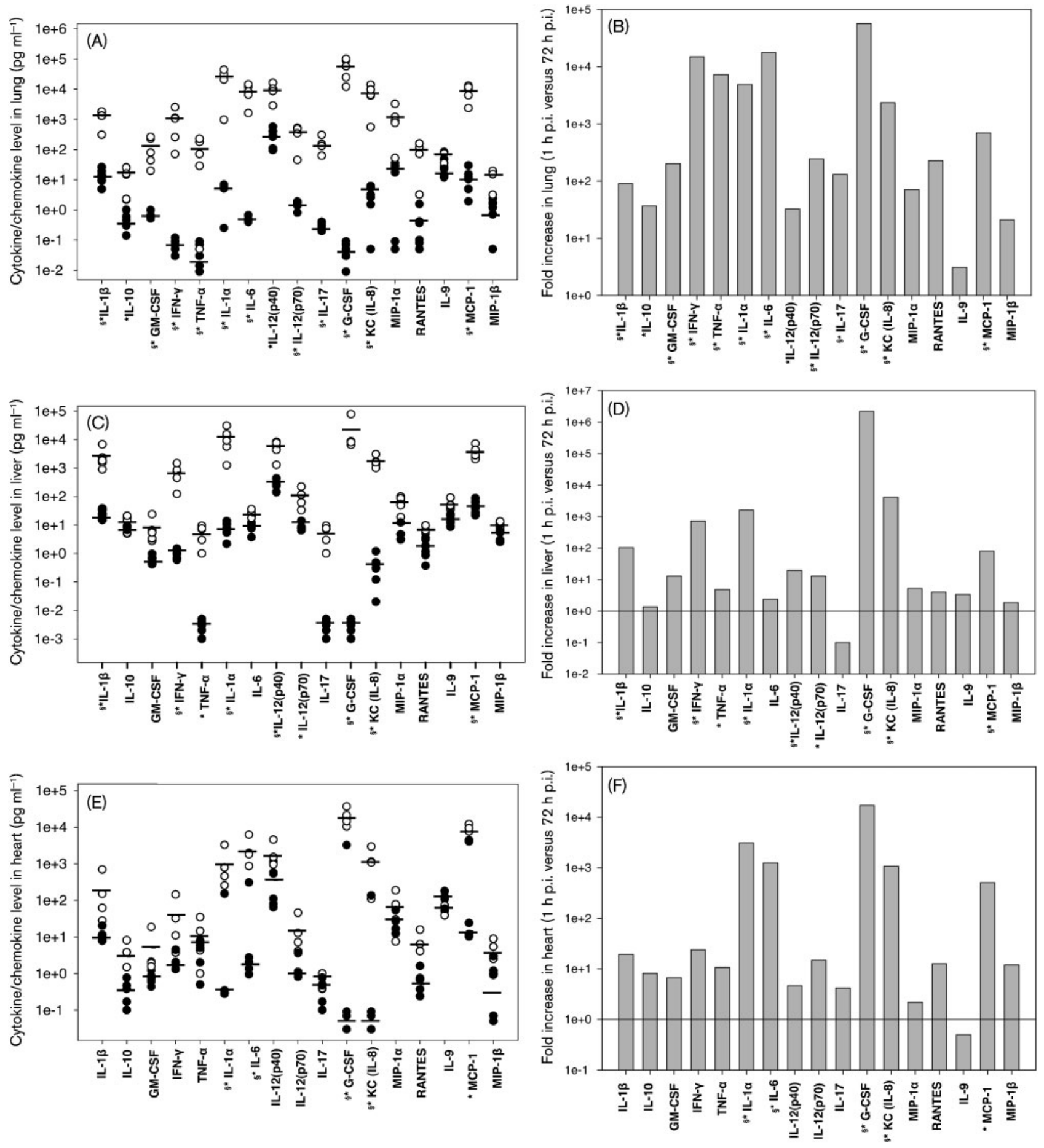
other studies that have indicated that the slightest delay in antibiotic (doxycycline, ciprofloxacin or chloramphenicol) treatment results in death from pneumonic plague (Gradon, 2002; Inglesby et al., 2000). Our own studies also indicated that if the antibiotic treatment (e.g. levofloxacin) was delayed in mice by $36-48 \mathrm{~h}$ after infection with $Y$. pestis CO92 via the intranasal route, animals succumbed to infection (data not shown). The histopathology reported herein in this aerosol model was quite similar to that that we (Sha et al., 2008) and others
(Bubeck et al., 2007; Lathem et al., 2005) reported, having used the intranasal model, i.e. immediate effects were seen in mouse lungs by $24 \mathrm{~h}$ p.i., as well as liver and spleen involvement beginning $48 \mathrm{~h}$ p.i. In contrast, an earlier study that utilized an aerosol model reported no remarkable changes in the livers of infected mice for up to $72 \mathrm{~h}$ p.i. (Smith, 1959). These differences between the studies may be due to variations in bacterial strain or dose, mouse strain, or aerosolization conditions (e.g. airflow through the aerosol chamber) (Glynn et al., 2005).
(G)

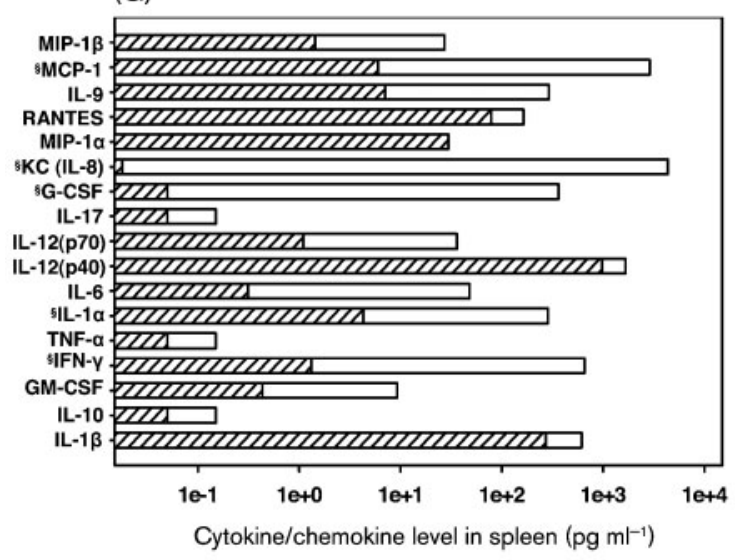

(I)

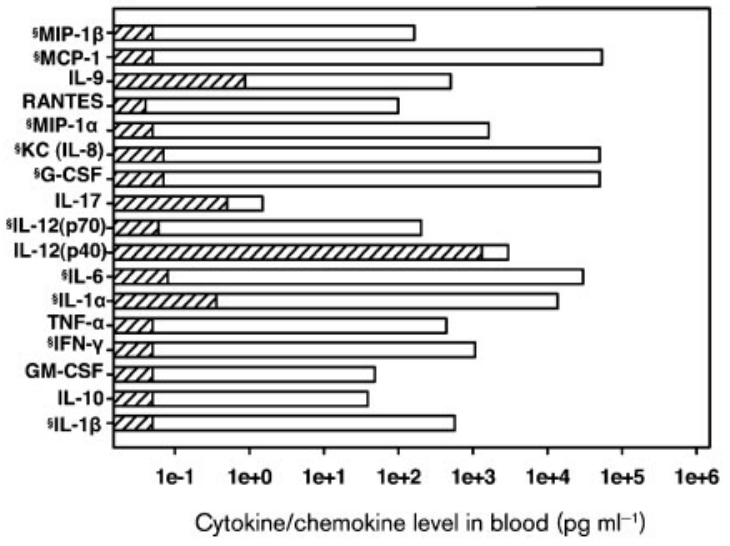

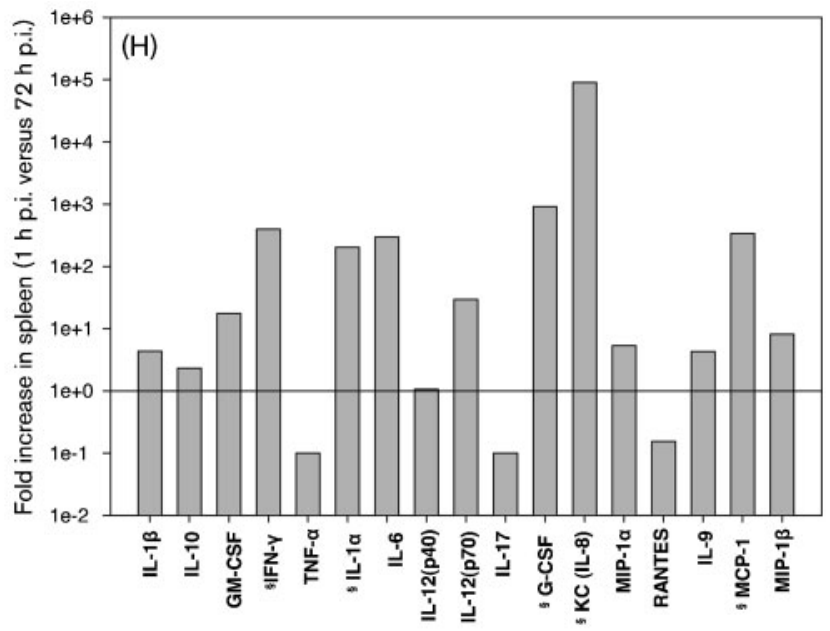

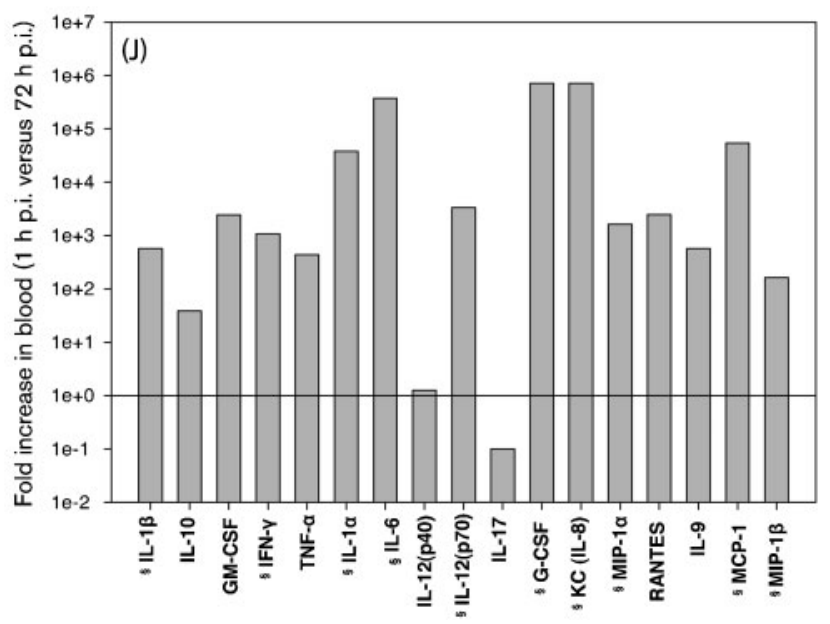

Fig. 4. Cytokine and chemokine levels in various organ homogenates at 1 ( or hatched bars for pooled samples in $\mathrm{G}$ and $\mathrm{I}$ ) and 72 h p.i. ( $\bigcirc$ or white bars for pooled samples in $\mathrm{G}$ and I). Following aerosolization, 20 mice were killed at 1, 24, 48 and $72 \mathrm{~h}$ p.i. (five mice per group, except where indicated). For cytokine analysis, tissue homogenates and sera at 1 and $72 \mathrm{~h} \mathrm{p.i.}$ were examined. Homogenates of the lungs (A), liver (C), heart (E, four mice at $1 \mathrm{~h} \mathrm{p.i.)}$ and spleen $(\mathrm{G})$ and the sera (I) of each mouse were analysed by Bio-Plex for cytokine and chemokine levels. (A-F) Overlapping of some data points may prevent one from seeing all five points; *significant increases in cytokine or chemokine concentration at $72 \mathrm{~h}$ p.i. $(P<0.05$, Student's $t$ test); the bar represents the mean cytokine or chemokine level at each time point. A small amount of spleen homogenate at $72 \mathrm{~h} \mathrm{p.i.}$ required pooling of the samples $(\mathrm{G}$ and $\mathrm{H})$ ). Both a lack of sample and moribund mice made it necessary to pool both the $72 \mathrm{~h}$ p.i. blood samples (I and J). For consistency, we also pooled the $1 \mathrm{~h}$ p.i. samples. Data were plotted on a log scale in order to allow us to visualize all of the data points. $\S, 100-$ to 1000 -fold or greater increase in the cytokine/chemokine levels from 1 to $72 \mathrm{~h}$ p.i. (B, D, F, H and J) Fold increase of each cytokine and chemokine between 1 and $72 \mathrm{~h}$ p.i. 


\section{Bacterial dissemination following aerosolization over a $72 \mathrm{~h}$ period}

At 1, 24, 48 and $72 \mathrm{~h}$ p.i. with $Y$. pestis CO92, mice were anaesthetized, and blood was drawn via cardiac puncture, after which the animals were killed, and the organs were harvested, homogenized, and cultured on SBA, as described in Methods. As expected, a general upward trend in the number of bacteria was found in different organs, and this was indicative of a successful bacterial infection. Bacteria multiplied in the lungs in the first $24 \mathrm{~h}$ p.i., having increased in number by $1-2$ logs, but the most substantial increase was by 3 logs between 48 and $72 \mathrm{~h}$ p.i. (Fig. 3A). An increase in the number of bacteria (by approx. 5 logs) reported at $72 \mathrm{~h}$ p.i. was not considered a statistically significantly increase compared with bacterial numbers $1-24 \mathrm{~h}$ p.i.; this was because of a single mouse in which only a marginal increase in bacterial number was noted when compared with the other four mice at $72 \mathrm{~h}$ p.i. Similar changes in bacterial numbers over the course of infection have been seen in an earlier aerosol study (Smith et al., 1957), and in other reports in which mice were infected via the intranasal route (Bubeck et al., 2007; Lathem et al., 2005). In contrast, in our most recent study using the intranasal route, we observed an initial drop in the number of bacteria in the lungs of mice at $24 \mathrm{~h}$ p.i., but noted rises similar to those described above in the numbers of bacteria up to $72 \mathrm{~h}$ p.i. (Sha et al., 2008).

A progressive increase in the number of bacteria in other mouse organs, such as the liver (Fig. 3B), heart (Fig. 3C) and spleen (Fig. 3D), was noted over the $72 \mathrm{~h}$ infection period, indicating bacterial dissemination throughout the body, and multi-organ involvement. The greatest increase in bacterial numbers in these organs was also seen between 48 and $72 \mathrm{~h}$ p.i., with statistically significant increases in the liver and spleen between these two time points. As seen in the lungs, a single mouse prevented the increase in bacterial numbers seen in the heart at $72 \mathrm{~h}$ p.i. from being statistically significant compared with other earlier time points after infection. Likewise, a significant increase in bacterial numbers cultured from the blood was noted at $72 \mathrm{~h}$ p.i. when the samples were compared with the $1 \mathrm{~h}$ control samples (Fig. 3E). We believe our inability to culture bacteria from the blood at 24 and $48 \mathrm{~h}$ p.i. indicated a rapid dissemination of bacteria to peripheral organs. Alternatively, viable bacteria might have been circulating in the bloodstream inside the phagocytic cells, and hence we were unable to detect them at earlier time points of infection. In our future studies, we will compare bacterial growth in serum samples and lysed total leukocytes to validate this hypothesis. However, at $72 \mathrm{~h}$ p.i., the infection was overwhelming, resulting in the detection of a significant number of bacteria in the blood. This multi-organ involvement has been noted in previous studies utilizing the intranasal model of pneumonic plague (Lathem et al., 2005; Sha et al., 2008), and earlier aerosol models (Smith et al., 1957; Smith, 1959).

\section{In vivo cytokine analysis}

The organ homogenates and blood from infected mice at 1 and $72 \mathrm{~h}$ p.i. were analysed for cytokine profiles using BioPlex, as described in Methods. We chose to compare the levels of cytokines and chemokines in control animals $(1 \mathrm{~h}$ p.i.) with the levels in mice at $72 \mathrm{~h}$ p.i., based on our previous study in which we detected most changes in cytokine and chemokine levels in the sera at the later time point of $96 \mathrm{~h}$ p.i. (Sha et al., 2008). The sera and tissues from animals $1 \mathrm{~h}$ p.i. had similar levels of cytokines and chemokines as noted in the sera and tissues of uninfected (subjected to aerosolization with the diluent alone) control mice. For the 23 cytokines and chemokines in the Bio-Plex mouse panel, differences in levels at the two time points were noted in 17 tissue homogenates, as displayed in Fig. 4. For the remaining six cytokines and chemokines in the panel, we noticed either no detectable level at both 1 and $72 \mathrm{~h}$ p.i., or the levels were unusually high in the control animals, and so these results were left out of our analysis. There were statistically significant increases in the concentrations of 13 of the cytokines and chemokines detected in the lung homogenates at $72 \mathrm{~h}$ p.i. when these samples were compared with the $1 \mathrm{~h}$ control sample, while the remaining four [macrophage inflammatory protein (MIP)-1 $\alpha$, RANTES (regulated upon activation, normal T cell-expressed and -secreted), IL-9, and MIP-1 $\beta$ ] showed an increasing trend (Fig. 4A). Cytokines and chemokines that exhibited 100- to 1000 -fold or greater increases from $1 \mathrm{~h}$ to $72 \mathrm{~h}$ p.i. are denoted with the symbol $\S$ (Fig. 4B). Specifically of interest were the dramatic increases in proinflammatory cytokines, such as IL- $1 \beta$, IL- $1 \alpha$, interferon (IFN)- $\gamma$, IL12(p70), tumour necrosis factor (TNF)- $\alpha$, and IL-6 at $72 \mathrm{~h}$ p.i. compared with their levels in the control; previous studies utilizing an intranasal model have shown similar increases in various cytokines and chemokines (Bubeck et al., 2007; Lathem et al., 2005; Sha et al., 2008). Of additional interest were the substantial increases seen in the levels of granulocyte macrophage colony-stimulating factor (GM-CSF) and granulocyte colony-stimulating factor (G-CSF), which function in the proliferation and survival of monocytes and neutrophils, respectively, as well as in the levels of the chemoattractants MCP-1 (monocytes) and $\mathrm{KC}$, which is the human equivalent of IL-8 (neutrophils).

In the liver homogenates (Fig. 4C), we noted significant increases in nine of the cytokines and chemokines in the panel at $72 \mathrm{~h}$ p.i., while most others showed an increasing trend. We observed the most dramatic increases in IL- $1 \beta$, IL- $1 \alpha$, IFN- $\gamma$, IL-12(p70), G-CSF and the chemoattractants MCP-1 and KC (100- to 1000-fold or greater, denoted with the symbol $\$$, Fig. 4D). The heart (Fig. 4E, F) also exhibited significant and dramatic increases (100- to 1000 -fold or greater, denoted with the symbol $\S$ ) in the levels of IL- $1 \alpha$, IL-6, G-CSF, KC and MCP-1 at 72 h p.i. All other cytokine and chemokine levels detected in the heart showed an increasing trend from 1 to $72 \mathrm{~h}$ p.i.

The spleen homogenates (Fig. 4G, H) and blood samples (Fig. 4I, J) of the five mice at each time point were pooled, 
preventing us from statistically analysing these data; however, the figures represent typical results from two independent experiments. We had to pool these samples because of the thickness of the blood and tissue homogenates; the thickness was the result of the development of overwhelming infection, and it made it difficult to filter out small samples from each mouse. We noted an upward trend of cytokine and chemokine levels following infection with $Y$. pestis CO92; the results were similar to those seen in the lungs, liver and heart of mice at $72 \mathrm{~h}$ p.i., and indicated a severe systemic proinflammatory response late in infection. These data were in agreement with our recent studies documenting the effect of $Y$. pestis infection when the bacteria were introduced into mice via the intranasal route, as there was an increase in the production of various cytokines and chemokines in the sera (Sha et al., 2008). Specifically of interest in the spleen were the substantial increases (denoted with the symbol $\$$, and represented by fold increase in Fig. 4H, J) in the levels of MCP-1, KC, GCSF, IL- $1 \alpha$ and IFN $-\gamma$, while the blood showed dramatic increases in the levels of the MIP- $1 \beta$, MIP- $1 \alpha$, MCP, IL- $1 \beta$, IL- $1 \alpha$, IFN- $\gamma$, IL-12(p70), IL-6, KC and G-CSF at $72 \mathrm{~h}$ p.i. These data indicated that within $72 \mathrm{~h}$ after infection, powerful and systemic recruitment of inflammatory cells, and release of proinflammatory cytokines, were initiated as a result of infection with aerosolized $Y$. pestis.

\section{Conclusions}

The virulent bacterium $Y$. pestis CO92 causes a severe infection and illness (pneumonia) in humans and animals when given by the inhalation routes. Thus, the present study provided a comprehensive examination of infection kinetics of $Y$. pestis when administered to mice by the aerosol route using a whole-body Madison chamber. Tissue damage was evident at $24 \mathrm{~h}$ p.i. in the lungs, as assessed by histopathology, and between 48 and $72 \mathrm{~h}$ p.i. in peripheral tissues, as demonstrated by both histopathological and proinflammatory cytokine analyses. Bacteria increased in numbers within $24 \mathrm{~h}$ p.i. in the lungs, and between 24 and $72 \mathrm{~h}$ p.i. they disseminated rapidly to the peripheral tissues. These data indicated the similarity of the model to the more commonly used intranasal model, and that both inhalational models are appropriate for the study of pneumonic plague. However, to mimic bacterial infection following an intentional release of virulent $Y$. pestis in the environment as a result of bioterrorism, the aerosol model of plague is more suitable for studying progression of the disease. In this report, we have fully characterized the mouse model in terms of bacterial dissemination, histopathology and cytokine profiling after aerosolization of $Y$. pestis CO92.

\section{ACKNOWLEDGEMENTS}

This research was supported by NIH/NIAID grants AI064389 and N01-AI-30065, the John Sealy Endowment Fund for Biomedical Research, University of Texas Medical Branch, Galveston, TX, USA, and UK-based PowderMed Ltd. (now part of Pfizer). S. L. A. is an NIH T32 pre-doctoral Emerging and Tropical Infectious Diseases training grant recipient (AI07526). We thank Ms Mardelle Susman for her careful review of the manuscript.

\section{REFERENCES}

Anderson, G. W., Jr, Leary, S. E., Williamson, E. D., Titball, R. W., Welkos, S. L., Worsham, P. L. \& Friedlander, A. M. (1996). Recombinant $\mathrm{V}$ antigen protects mice against pneumonic and bubonic plague caused by F1-capsule-positive and -negative strains of Yersinia pestis. Infect Immun 64, 4580-4585.

Andrews, G. P., Heath, D. G., Anderson, G. W., Jr, Welkos, S. L. \& Friedlander, A. M. (1996). Fraction 1 capsular antigen (F1) purification from Yersinia pestis CO92 and from an Escherichia coli recombinant strain and efficacy against lethal plague challenge. Infect Immun 64, 2180-2187.

Bubeck, S. S., Cantwell, A. M. \& Dube, P. H. (2007). Delayed inflammatory response to primary pneumonic plague occurs in both outbred and inbred mice. Infect Immun 75, 697-705.

Cathelyn, J. S., Crosby, S. D., Lathem, W. W., Goldman, W. E. \& Miller, V. L. (2006). RovA, a global regulator of Yersinia pestis, specifically required for bubonic plague. Proc Natl Acad Sci U S A 103, 1351413519 .

Doll, J. M., Zeitz, P. S., Ettestad, P., Bucholtz, A. L., Davis, T. \& Gage, K. (1994). Cat-transmitted fatal pneumonic plague in a person who traveled from Colorado to Arizona. Am J Trop Med Hyg 51, 109-114.

Glynn, A., Roy, C. J., Powell, B. S., Adamovicz, J. J., Freytag, L. C. \& Clements, J. D. (2005). Protection against aerosolized Yersinia pestis challenge following homologous and heterologous prime-boost with recombinant plague antigens. Infect Immun 73, 5256-5261.

Gradon, J. D. (2002). Plague pneumonia. Curr Infect Dis Rep 4, 244248.

Guyton, A. C. (1947). Measurement of the respiratory volumes of laboratory animals. Am J Physiol 150, 70-77.

Heath, D. G., Anderson, G. W., Jr, Mauro, J. M., Welkos, S. L., Andrews, G. P., Adamovicz, J. \& Friedlander, A. M. (1998). Protection against experimental bubonic and pneumonic plague by a recombinant capsular F1-V antigen fusion protein vaccine. Vaccine 16, 1131-1137.

Hill, J., Eyles, J. E., Elvin, S. J., Healey, G. D., Lukaszewski, R. A. \& Titball, R. W. (2006). Administration of antibody to the lung protects mice against pneumonic plague. Infect Immun 74, 3068-3070.

Inglesby, T. V., Dennis, D. T., Henderson, D. A., Bartlett, J. G., Ascher, M. S., Eitzen, E., Fine, A. D., Friedlander, A. M., Hauer, J. \& other authors (2000). Plague as a biological weapon: medical and public health management. Working Group on Civilian Biodefense. JAMA 283, 2281-2290.

Jones, T., Adamovicz, J. J., Cyr, S. L., Bolt, C. R., Bellerose, N., Pitt, L. M., Lowell, G. H. \& Burt, D. S. (2006). Intranasal protollin/F1-V vaccine elicits respiratory and serum antibody responses and protects mice against lethal aerosolized plague infection. Vaccine 24, 16251632.

Krishna, G. \& Chitkara, R. K. (2003). Pneumonic plague. Semin Respir Infect 18, 159-167.

Lathem, W. W., Crosby, S. D., Miller, V. L. \& Goldman, W. E. (2005). Progression of primary pneumonic plague: a mouse model of infection, pathology, and bacterial transcriptional activity. Proc Natl Acad Sci U S A 102, 17786-17791. 
Lathem, W. W., Price, P. A., Miller, V. L. \& Goldman, W. E. (2007). A plasminogen-activating protease specifically controls the development of primary pneumonic plague. Science 315, 509-513.

Perry, R. D. \& Fetherston, J. D. (1997). Yersinia pestis - etiologic agent of plague. Clin Microbiol Rev 10, 35-66.

Peterson, J. W., Comer, J. E., Baze, W. B., Noffsinger, D. M., Wenglikowski, A., Walberg, K. G., Hardcastle, J., Pawlik, J., Bush, K. \& other authors (2007). Human monoclonal antibody AVP-21D9 to protective antigen reduces dissemination of the Bacillus anthracis Ames strain from the lungs in a rabbit model. Infect Immun 75, 3414-3424.

Riedel, S. (2005). Plague: from natural disease to bioterrorism. Proc (Bayl Univ Med Cent) 18, 116-124.

Roy, C. J. \& Pitt, M. L. M. (2005). Infectious Disease Aerobiology: Aerosol Challenge Methods. Boca Raton, FL: CRC Press.

Sha, J., Agar, S. L., Baze, W. B., Olano, J. P., Fadl, A. A., Erova, T. E., Wang, S., Foltz, S. M., Suarez, G. \& other authors (2008). Braun lipoprotein (Lpp) contributes to the virulence of yersiniae: potential role of Lpp in inducing bubonic and pneumonic plague. Infect Immun 76, 1390-1409.

Smith, P. N. (1959). Pneumonic plague in mice: gross and histopathology in untreated and passively immunized animals. J Infect Dis 104, 78-84.

Smith, P. N., McCamish, J., Seely, J. \& Cooke, G. M. (1957). The development of pneumonic plague in mice and the effect of paralysis of respiratory cilia upon the course of infection. I Infect Dis 100, 215-222.

Williamson, E. D., Stagg, A. J., Eley, S. M., Taylor, R., Green, M., Jones, S. M. \& Titball, R. W. (2007). Kinetics of the immune response to the $(\mathrm{F} 1+\mathrm{V})$ vaccine in models of bubonic and pneumonic plague. Vaccine 25, 1142.

Edited by: P. van der Ley 